OPEN ACCESS

Edited by:

Lars Kaestner,

Saarland University, Germany

Reviewed by:

Caroline Le Van Kim

Paris Diderot University, France

Federico Quaini,

Università degli Studi di Parma, Italy

Anna Rita Migliaccio,

Icahn School of Medicine at Mount

Sinai, United States

*Correspondence:

Emile van den Akker

e.vandenakker@sanquin.nl

${ }^{\dagger}$ These authors have contributed equally to this work.

Specialty section:

This article was submitted to Membrane Physiology and membrane biophysics,

a section of the journal

Frontiers in Physiology

Received: 28 February 2018 Accepted: 12 June 2018

Published: 11 July 2018

Citation:

Ovchynnikova E, Aglialoro F von Lindern $M$ and van den Akker $E$

(2018) The Shape Shifting Story

of Reticulocyte Maturation.

Front. Physiol. 9:829

doi: 10.3389/fphys.2018.00829

\section{The Shape Shifting Story of Reticulocyte Maturation}

\author{
Elina Ovchynnikova ${ }^{1,2 t}$, Francesca Aglialoro ${ }^{1,2+}$, Marieke von Lindern ${ }^{1,2}$ and \\ Emile van den Akker ${ }^{1,2 *}$
}

'Department of Hematopoiesis, Sanquin Research, Amsterdam, Netherlands, ${ }^{2}$ Landsteiner Laboratory, Academic Medical Center, University of Amsterdam, Amsterdam, Netherlands

The final steps of erythropoiesis involve unique cellular processes including enucleation and reorganization of membrane proteins and the cytoskeleton to produce biconcave erythrocytes. Surprisingly this process is still poorly understood. In vitro erythropoiesis protocols currently produce reticulocytes rather than biconcave erythrocytes. In addition, immortalized lines and iPSC-derived erythroid cell suffer from low enucleation and suboptimal final maturation potential. In light of the increasing prospect to use in vitro produced erythrocytes as (personalized) transfusion products or as therapeutic delivery agents, the mechanisms driving this last step of erythropoiesis are in dire need of resolving. Here we review the elusive last steps of reticulocyte maturation with an emphasis on protein sorting during the defining steps of reticulocyte formation during enucleation and maturation.

Keywords: reticulocytes, erythropoiesis, differentiation, protein sorting, enucleation, maturation

\section{INTRODUCTION}

Production of red blood cells for transfusion can have several distinct benefits for healthcare and patient wellbeing (Douay and Andreu, 2007; Goodnough and Murphy, 2014; Shah et al., 2014; Benedetto et al., 2015). Alloimmunization is one of the major complications of blood transfusion and particularly affects patients who are frequently transfused. Observational studies conducted on random patients who received incidental transfusions demonstrated 1-3\% alloimmunization. However, in patients with sickle cell disease (SCD) who receive chronic transfusions this can increase to $8 \%$ or even as high as 76\% (Campbell-Lee and Kittles, 2014; Alkindi et al., 2017). In severe cases the only option available for the patient is a stem cell transplantation, which carries significant risk on its own. In vitro production of transfusable red blood cells can ensure better availability of matched blood, helping in the reduction of alloimmunization and contributing to more efficient treatment of such diseases as hemoglobinopathies and MDS. Apart from possible immune reactions, donor blood can be a source of blood borne diseases such as Hepatitis B and HIV. Produced in vitro red blood cells will be safe in terms of infections spreading. Another application for in vitro cultured red cells may be as vehicle for therapeutic agents, delivering cargo to specific parts in the body (Muzykantov, 2010; Crossan et al., 2011). Production of cultured red blood cells, however, faces a couple of challenges. First is quantity of production. One unit of blood transfused to the patient contains about 2 trillion red blood cells and annual transfusion need counts up to 90 million units in the world annually (World Health Organisation [WHO], 2017). Currently existing laboratory culture systems of red blood cells are not able to generate satisfactory number of red blood cells in efficient and cost-effective fashion, which need to be improved. Second challenge of red blood cells production is the quality of product. Existing laboratory culture systems give rise to 
reticulocytes of different stages of maturity using various culture systems and starting material depending or not depending on coculture with specific stromal cells (Migliaccio et al., 2002, 2010; Giarratana et al., 2005; Leberbauer et al., 2005; Miharada et al., 2006; van den Akker et al., 2010a; Shah et al., 2016; Trakarnsanga et al., 2017). Reticulocytes are immature red blood cells that lost their nucleus but still retain residual RNA. Reticulocytes can perform the main function of red blood cells-oxygen transport. However, they have not yet adopted the unique biconcave shape of mature red blood cells that ensures their stability and flexibility to withstand blood flow shear stress. Luc Douay and coworkers published unique research in which they performed autologous transfusion of ${ }^{51} \mathrm{Cr}$ labeled in vitro cultured red blood cells to a human volunteer (Giarratana et al., 2011), reporting a reticulocyte half-life of approximately 26 days post injection. The life span of red blood cell is 120 days, which suggests that the in vitro cultured reticulocytes exhibit high clearance, possibly due to their low stability and immaturity. Effective use of cultured red blood cells for transfusion purposes may benefit from maturation of reticulocytes to mature erythrocytes, a process that is ill-defined and poorly understood. It is known that after the enucleation process, reticulocytes enter the bloodstream where they complete their maturation into fully functional erythrocytes within 3 days (Chasis et al., 1989). The reticulocyte stage of erythroid differentiation is brief, however, involves an extensive array of changes. During maturation reticulocytes undergo membrane remodeling, lose up to $20 \%$ of membrane, eliminate residual organelles and RNA and gain bi-concaveness (Gronowicz et al., 1984). Understanding the processes and factors involved in maturation of reticulocytes is an important step toward development of culture system producing transfusionready red blood cells. This review covers recent findings in the process of reticulocyte maturation with an implication in red blood cell production. Table $\mathbf{1}$ indicates commonly used abbreviations throughout the review.

\section{THE ELUSIVE AND ILL-DEFINED ROLE OF MACROPHAGES WITHIN ERYTHROBLASTIC ISLANDS}

Terminal erythroid differentiation within bone marrow as well as during ontogeny takes place at specialized multicellular structures called erythroblastic islands (Bessis, 1958; Mohandas and Prenant, 1978) (Figure 1). Erythroblastic islands are composed of a central macrophage surrounded by differentiating erythroblasts and reticulocytes. It is unknown whether the primary function of the central macrophage is mainly to engulf and digest the expulsed nuclei, or whether the mutual interaction between the macrophage and the maturing erythroblasts contribute to the erythroid differentiation program and/or macrophage function. Adding to this confusion are the numerous knockouts that interfere with putative interaction partners facilitating the association between erythroid and macrophages that may or may not result in anemia (Sadahira et al., 1995; Hanspal et al., 1998b; Lee et al., 2006; Soni et al., 2006; Heideveld and van den Akker, 2017). Equally confusing is
TABLE 1 | Abbreviations and function.

\begin{tabular}{|c|c|}
\hline Acronym & Full name \\
\hline MDS & Myelodysplastic syndrom \\
\hline HIV & Human Immunodeficiency Virus \\
\hline BMP-4 & Bone Morphogenetic Protein 4 \\
\hline IL-6 & Interleukin 6 \\
\hline TNF-alpha & Tumor Necrosis Factor alpha \\
\hline INF-gamma & Interferon gamma \\
\hline VCAM-1 & Vascular Cell Adhesion Molecule 1 \\
\hline ICAM-4 & Intracellular Adhesion Molecule 4 \\
\hline Gas6 & Growth arrest-specific 6 \\
\hline Epo & Erythropoietin \\
\hline PI3K & Phosphatidylinositol-4,5-bisphosphate 3-kinase \\
\hline $\mathrm{PKB}$ & Protein Kinase B \\
\hline TAM-receptor & Tyrosine Activation Motif receptor \\
\hline CAR & Contractile Actomyosine Ring \\
\hline CRIK & Citron Rho-interacting Kinase \\
\hline Rho-GTPase & Rho-Guanosine TriPhosphate \\
\hline MLC2 & Myosin regulatory Light Chain 2 \\
\hline HAT & Histone Acetyl Transferase \\
\hline HDAC & Histone Deacetylase \\
\hline Gnc5 & General control non-derepressible 5 \\
\hline MERTK & Proto-oncogene tyrosine-protein kinase MER \\
\hline CD34 & Cluster of differentiation; transmembrane phosphoglycoprotein \\
\hline RhAG & Rh-Associated Glycoprotein \\
\hline GPC & Glycophorin C \\
\hline EMP & Erythroblast Macrophage Protein \\
\hline CD147 & Basignin \\
\hline $\mathrm{Xk}$ & Kell blood group precursor \\
\hline $\mathrm{Rh}$ & Rhesus \\
\hline CD47 & Integrin Associated Protein \\
\hline CD49d & Integrin alpha subunit \\
\hline CD71 & Transferrin Receptor 1 (Trf1) \\
\hline TO & Thiazole Orange \\
\hline KCC & Potassium Chloride Cotransporter \\
\hline LPA & Lysophosphatidic Acid \\
\hline SCD & Sickle Cell Disease \\
\hline Lu & Lutheran \\
\hline BCAM & Basal Cell Adhesion Molecule \\
\hline PKA & Protein Kinase A \\
\hline GLUT4 & Glucose transporter type 4 \\
\hline GPA & Glycophorin A \\
\hline MVEs & Multivesicular Endosomes \\
\hline ESCRT & Endosomal sorting complexes required for transport \\
\hline AQP1 & Aquaporin 1 \\
\hline MVB & Multivesicular Body \\
\hline LC3 & Light chain 3b \\
\hline Rab11 & Ras-related protein \\
\hline LW & Landsteiner-Wiener \\
\hline CD44 & Cell surface glycoprotein \\
\hline
\end{tabular}

the observation that specific ablation of CD163+ macrophages in mice, although somewhat attenuating erythropoiesis, does not result in anemia (Chow et al., 2011). Differentiating erythroblasts follow distinct morphological changes that define the nomenclature. The early erythroblast stage is characterized 


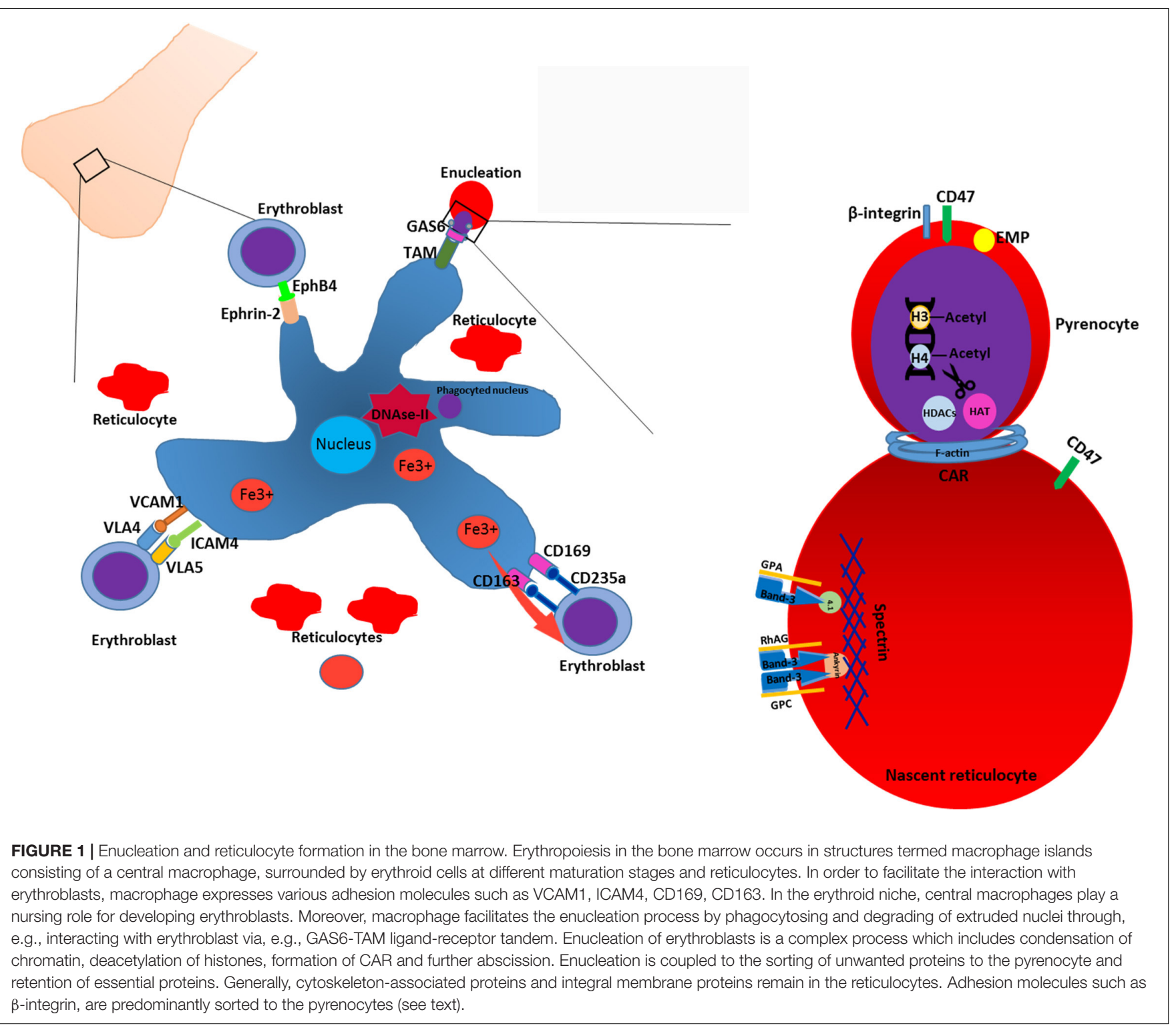

by a large cell size, $12-20 \mu \mathrm{m}$ in diameter, with a nucleus that occupies up to $80 \%$ of the cell volume. Nuclei of erythroblasts contain a large number of nucleoli. Basophilic erythroblasts are smaller and characterized by increased condensation of chromatin, combined with basophilic cytoplasm. Polychromatic erythroblasts are characterized by emerging hemoglobinization of the cytoplasm and irregularly condensed nuclei. In orthochromatic erythroblasts hemoglobinization is nearly completed, and nuclei are pyknotic. In this stage the cells do not expel several nuclei expulsion and differentiation to reticulocytes. The concept of erythroblastic islands was introduced by Bessis (1958) who analyzed transmission electron micrographs of bone marrow sections (Bessis, 1958). Bessis hypothesized that central macrophages play a supporting role during erythropoiesis by providing ferritin to the cells and by phagocytosis of expelled nuclei (Bessis and Breton-Gorius, 1962). The hypothesis of Bessis was reinforced by the study of Mohandas on hyper transfused rats (Mohandas and Prenant, 1978) in which erythropoiesis and the number of erythroblast-macrophage clusters is suppressed. Single stimulation of these rats with erythropoietin induced synchronous differentiation of resting erythroblast precursor cells. These experiments allowed to detect the individual clusters of erythroblasts within the bone marrow and link the formation of these multicellular structures to erythropoiesis. Quantitative light and electron microscopy of rat bone marrow sections demonstrated that islands form far from the sinuses accommodate mostly pro-erythroblasts, while the islands situated in the proximity to bone marrow sinuses contained more of differentiating erythroblasts and reticulocytes (Mohandas and Prenant, 1978; Yokoyama et al., 2003). It was proposed by Yokoyama et al. (2003) that erythroblastic islands can migrate toward the sinuses as differentiation of erythroid cells progresses, albeit through unknown mechanisms. This hypothesis, however, requires experimental reinforcement as it is 
unknown what signals, intrinsic or extrinsic, drive this apparent dynamic process. Co-culture of CD34+ cells with stromal cells or macrophages results in nearly complete enucleation, compared to feeder-free cultures (Giarratana et al., 2005 \#729; Fujimi et al., 2008; Lu et al., 2008 \#1723). Importantly, other studies have shown that erythroid terminal differentiation to complete enucleation can occur independent of central macrophages and that resulting reticulocytes can mature to biconcave erythrocytes upon injection into the bloodstream (Leberbauer et al., 2005; Ji et al., 2010; van den Akker et al., 2010a; Giarratana et al., 2011). So, although for enucleation and reticulocyte formation macrophages appear to be dispensable, macrophages may provide signals that optimize specific but ill-defined erythroid maturation processes that may be crucial for the eventual reticulocyte stability and function. In addition, specific culture systems/protocols may be more suitable to investigate specific signal transduction and transcriptional programs induced by the interplay between macrophages and erythroid cells and may for instance only manifest upon suboptimal culture conditions. For instance, macrophages within the erythroblastic island regulate erythropoiesis by multiple mechanisms including secretion of soluble factors and cell-cell contact. Macrophages have been shown to secrete BMP4, which can stimulate proliferation of erythroblasts (Millot et al., 2010; Heideveld et al., 2015). Macrophages also support erythropoiesis by secreting ferritin which is later taken up by erythroblasts via transferrin receptor or endocytosis (Meyron-Holtz et al., 1999; Leimberg et al., 2008; Kim et al., 2015). Secretion of IL-6, TNF- $\alpha$, and INF- $\gamma$ by macrophages down-regulates erythroid differentiation, while TGF- $\beta$ suppresses proliferation of early erythroblasts, and enhances differentiation (Zermati et al., 2000; Bohmer, 2004). Direct cell-cell interactions also regulate erythropoiesis within the islands. Several adhesion molecules have been identified that direct contact of erythroblasts with the central macrophage. Emp knockout mice die perinatal due to severe defects in hematopoiesis and have a complete lack of F4/80 erythroblastic island macrophages, whilst erythroid cells display defects in enucleation and undergo increased apoptosis (Hanspal et al., 1998b). Another protein described to mediate erythroid-macrophage interaction and which can be used as a marker of central macrophages is VCAM-1 (Chow et al., 2011). Erythroblasts utilize $\alpha 4 \beta 1$ integrin and ICAM4 to bind to VCAM-1 and establish a tight contact with the macrophage and neighboring erythroblasts (Palis, 2016; Seu et al., 2017). Blocking of $\alpha 4 \beta$ 1integrin with antibodies decreased cell proliferation and increased apoptosis in vitro and arrests erythropoiesis at E12 in $\alpha 4$ deficient mice (Sadahira et al., 1995; Lee et al., 2006). Interestingly though VCAM knockout mice do not display any phenotype regarding erythropoiesis, shedding doubt on whether VCAM is the interaction partner of $\alpha 4 \beta 1$ integrin (Ulyanova et al., 2016). Erythroblasts themselves can modulate inhibitory signaling from macrophages. Erythropoietin induces the secretion of Gas6 by erythroblasts which enhances the survival response to Epo-receptor signaling through PI3K and PKB-kinase signaling (Angelillo-Scherrer et al., 2008) and may function to facilitate phagocytosis of extruded nuclei through GAS6-dependent TAM-receptor present on central macrophages, which are expressed on human bone marrow and fetal liver macrophages (Toda et al., 2014; Heideveld and van den Akker, 2017). So although specific partners that facilitate the interaction between erythroid cells and macrophages as well as paracrine signaling has been found, the precise role of the central macrophage to the differentiation process of erythroid cells remains ill-defined. Recent phenotypic analysis of central macrophage populations in human bone marrow and fetal liver, together with the development of in vitro models now allows for in vitro experiments that could shed further light onto this elusive macrostructure (Hom et al., 2015; Belay et al., 2017; Heideveld and van den Akker, 2017; Seu et al., 2017).

\section{ENUCLEATION}

Enucleation of late stage erythroblasts or orthochromatic normoblasts is a unique cellular process that gives rise to reticulocytes [also reviewed in (Migliaccio, 2010)]. The only other cells in the body that undergo enucleation are the cells in the lens of our eyes. Before enucleation occurs, erythroblasts undergo cell cycle arrest, the chromatin condenses and the nucleus locates to the edge of the cell (Keerthivasan et al., 2011). Initially, enucleation was thought to be a specific form of apoptosis, which was based on microscopic detection of karyolysis and partial leakage of nuclear content into the cytoplasm (Simpson and Kling, 1967). In addition, the enucleation process in keratinocytes and fiber lens cells has also been described as a specific mechanism of programmed cell death (Bassnett, 1997; Yamamoto-Tanaka et al., 2014). However, reduction of caspase expression or inhibition of caspase activity demonstrated little to no involvement of caspases in erythroid enucleation (Carlile et al., 2004; Yoshida et al., 2005). Instead, recent evidence supports a model of asymmetric cytokinesis to separate the nucleus from the cell. This implies that the enucleating cell should display a cleavage furrow, the contractile actomyosine ring (CAR) and a stage of completion with abscission (Barr and Gruneberg, 2007) (Figure 1).

\section{The Mechanism of Enucleation}

A few players in cytokinesis were shown to play a role in enucleation. Citron Rho-interacting kinase (CRIK), a mitotic kinase known to interact with Rho-GTPases (Magor et al., 2015), regulates the length of astral microtubules and the orientation of the spindle in dividing cells. During enucleation, CRIK participates in the nuclear condensation and is involved in the formation of the CAR, possibly via interaction with MLC2 (Swartz et al., 2017). Another essential factor involved in enucleation is deacetylation of histones $\mathrm{H} 3$ and $\mathrm{H} 4$. Regulation of the acetylation status of those histones is carried out by enzymes histone acetyl transferase (HAT) and histone deacetylase (HDACs) (Ji et al., 2010). It has been shown that during late stage fetal erythropoiesis in mice Gcn 5 and c-Myc are downregulated and histone deacetylase 2 is upregulated, which results in the chromatin condensation and CAR formation (Jayapal et al., 2010). Konstantidinis described the formation of an actinmyosine ring upon initiation of enucleation. Actin-myosin ring 
contracts and the condensed nucleus is expelled out of the cell together with the thin rim of cytoplasm and plasma membrane to form the pyrenocyte (Konstantinidis et al., 2012). As well as in cytokinesis, the cytoskeleton plays an important role in erythroblast enucleation. Immunofluorescent and microscopic studies demonstrated the condensation of F-actin filaments and formation of CAR can be disrupted by cytochalasin and depends on Rho-GTPase activity and downstream mDia activation (Sawada et al., 1989; Ji et al., 2008). Formation of microtubules plays an essential role in nucleus polarization and extrusion. It has been shown that inhibition of PI3K decreases nuclear polarization efficiency and delays the enucleation in mice (Wang et al., 2012). The mechanism of asymmetric cytokinesis is sustained by a second process that may act concurrently: the formation and trafficking of vesicles during abscission. During this final stage of cytokinesis, vesicles move toward the midbody region, fuse and promote the separation of the daughter cell (Gromley et al., 2005). Vesicles mainly contribute to enucleation by supplying membranes to the progressing tip of the cleavage furrow and thus facilitating the separation of pyrenocyte from reticulocyte. Disruption of vesicle trafficking and inhibition of clathrin expression blocked the enucleation of erythroblasts, suggesting that vesicle trafficking has an essential role in nuclear extrusion process (Keerthivasan et al., 2010). Of note, the eventual phagocytosis of the extruded nuclei occurs via protein-S dependent and MERTK dependent processes (Toda et al., 2014). High enucleation rates have been described for in vitro culture systems that initiate from cord blood, fetal or adult CD34+ hematopoietic stem and progenitor cells (Leberbauer et al., 2005; van den Akker et al., 2010a; Giarratana et al., 2011). In contrast, enucleation is generally poor in immortalized cell lines and erythroid cells derived from induced pluripotent stem cells (Lapillonne et al., 2010; Kurita et al., 2013; Trakarnsanga et al., 2017) [reviewed by (Focosi and Amabile, 2017)]. Resolving the fine details of the enucleation process and events leading up to enucleation may facilitate and improve the production of erythrocytes from these immortal sources. This is important as immortalized lines provide a considerable simplification of the in vitro erythrocyte production method, can be genetically altered to express specific blood groups or therapeutic cargo and can be standardized.

\section{Protein Sorting During Enucleation}

During erythroblast enucleation, plasma membrane and cytoskeletal proteins undergo reorganization while the nucleus, surrounded by plasma membrane, separates from the reticulocyte. A key aspect of this process is the distribution of (membrane) proteins to the pyrenocyte and/or reticulocytes, which may be through active sorting of specific proteins or through non-specific simple redistribution. By consequence, protein sorting during enucleation determines the protein content of reticulocyte membranes and possibly also intracellular proteins. Cytoskeletal proteins important for erythrocyte function, such as the erythrocyte Spectrins, Ankyrin, and protein 4.1, remain within the nascent reticulocyte (Sawada et al., 1989; Wickrema et al., 1994). Integral membrane proteins that are associated with the cytoskeleton, such as Glycophorin A (Lee et al., 2004), Band 3, RhAG, GPC; (Salomao et al., 2010) are thus predominantly found on the reticulocyte. Some proteins are specifically sorted to the pyrenocyte, such as the erythroblast macrophage protein (EMP), $\beta 1$ integrin, Basignin (or CD147) and other adhesion molecules (Lee et al., 2004; Soni et al., 2006; Griffiths et al., 2012; Gautier et al., 2016). Distinct differences in the membrane composition of pyrenocytes and reticulocytes is likely to direct macrophages to phagocytose extruded nuclei. The mechanism of selective retention or exclusion of specific proteins within newly generated reticulocytes is still largely unknown but involve association with the erythroid specific Spectrin/Ankyrin cytoskeleton (Lee et al., 2004; Keerthivasan et al., 2011; Satchwell et al., 2016). During erythropoiesis the cytoskeleton is rearranged to facilitate large protein membrane networks that control the structural integrity of erythrocytes in the circulation through regulation of morphology by modulation of protein-cytoskeleton interactions or ion-transport (Bruce et al., 2009; van den Akker et al., 2010b; Satchwell et al., 2011). These networks can be roughly divided into an Ankyrin network and a junctional network [for review see (Bruce, 2008; van den Akker et al., 2010c)]. Mutations within proteins that comprise these complexes results in an array of erythrocyte specific diseases like hereditary spherocytosis and elliptocytosis [reviewed in (Da Costa et al., 2013; Gallagher, 2013)]. It has been proposed that inclusion of proteins within such networks facilitates reticulocyte retention during enucleation and vice versa localization to the nuclei upon non-inclusion (Satchwell et al., 2016). For instance GPC is located to the pyrenocyte in 4.1 deficient erythroblasts while this protein normally is sorted to reticulocytes, and GPA and $\mathrm{Rh}$-associated antigens are misdirected to the pyrenocyte in ankyrin deficient erythroblasts (Chasis et al., 1993; Satchwell et al., 2016). Aberrant sorting of proteins during enucleation may lay fundament to the development of pathologies like Hereditary spherocytosis and elliptocytosis. Mutations within membrane proteins or cytoskeleton proteins resulting in disturbed/weakened association between specific membrane proteins with the cytoskeleton lead to aberrant distribution to pyrenocytes (Salomao et al., 2010; Satchwell et al., 2016). A strict hierarchy is present that results from inter-dependency of specific membrane protein expression. For instance, loss of RhAG will lead to a complete loss of Rh proteins, a loss of Kell means a loss of $\mathrm{Xk}$, and loss of RhCE or protein 4.2 leads to a significantly reduced level of CD47 (Cherif-Zahar et al., 1996; Rivera et al., 2013; Mordue et al., 2017). Thus mutations within such "master" proteins may have significant domino effects on other proteins and thus the constitution and functionality of these large membrane complexes affecting erythrocyte stability. However, for proteins that are not part of these cytoskeletonmembrane protein hubs it is unknown if underlying mechanisms are specific or not. More work is required in order to determine the exact mechanism of protein sorting during enucleation. Understanding the nature of the sorting process can shed some light on the protein loss combined to the mutation in membrane-cytoskeleton complexes. This knowledge can aid in development of possible prevention and treatment of Hereditary spherocytosis and Elliptocytosis. In addition, direction of specific membrane proteins to these large membrane complexes may 
facilitate specific incorporation of therapeutic proteins to be used as delivery tools. A role for lipid composition to the sorting of proteins cannot be ruled out as it has been shown that lipid modifications and alterations during pathology associate with increased adhesion capabilities of erythrocytes (Hillery et al., 1996; Connor et al., 1997; Kuypers et al., 2007).

\section{MATURATION OF RETICULOCYTES IN THE CIRCULATION}

Although the term reticulocytes generally refers to enucleated erythroid cells that are not yet fully biconcave, one must appreciate these reticulocytes are a heterogeneous population of all stages in between enucleated reticulocytes and erythrocytes (Malleret et al., 2013; Ovchynnikova et al., 2017). These stages are characterized by progressive loss of RNA and membrane proteins that are cleared during maturation, such as CD71 or CD49d. In addition, reticulocyte maturation can be defined by size, morphology, biomechanical properties and metabolic state (Malleret et al., 2013). Diversity within the reticulocyte population was first described in early 1930's (Heilmeyer and Westhäuser, 1932). Based on brilliant Cresyl blue staining patterns, four stages were identified in the circulation: group I, group II, group III, and group IV (Heilmeyer and Westhäuser, 1932). Implementation of flow cytometry methods and use of Thiazole Orange (TO) to visualize RNA provided a more advanced reticulocyte maturity index classification system (Davis et al., 1995; Choi and Pai, 2001; Wollmann et al., 2014). This system, however, is proven to be inaccurate in certain conditions. Presence of hemoparasites and pathological erythrocyte inclusions such as Howell-Jolly bodies may result in false positive staining. Gradual loss of the transferrin receptor makes it an informative marker for reticulocyte maturation (Malleret et al., 2013). Based on CD71 staining of cord blood derived reticulocytes Malleret et al. (2013) described four stages of reticulocyte maturity namely CD71high, CD71medium, CD71low and CD71negative. Utilization of TO staining together with CD71 provides a more accurate distinction of various stages of reticulocyte maturation, mostly due to the fact that CD71 loss occurs prior to the loss of RNA. Based on CD71/TO dual staining it is possible to differentiate four stages of reticulocyte maturation from early reticulocytes $\mathrm{R} 1$ to late reticulocytes R4 (Malleret et al., 2013; Ovchynnikova et al., 2017). Upon release from the erythroblastic island, reticulocytes are irregularly shaped, multilobular cells that are far from being flexible compared to mature red blood cell (Mel et al., 1977; Malleret et al., 2013). To adopt a bi-concave morphology, stability, and the ability to deform these cells have to undergo a maturation process. Membrane-cytoskeleton rearrangement may be an important step allowing the transition from an unstructured reticulocyte to a morphologically biconcave and functional erythrocyte (Waugh et al., 1997, 2001). It takes 1-2 days in the circulation for the reticulocyte to obtain bi-concaveness and mature into fully functional erythrocytes (Chasis et al., 1989). Surprisingly, mature reticulocytes are stable and deformable as mature erythrocytes, while in young reticulocytes mechanical stability and membrane deformability are decreased (Chasis et al., 1989; Waugh et al., 1997). In addition, extracellular epitope exposure of specific membrane proteins is changing during reticulocyte maturation (Malleret et al., 2013; Ovchynnikova et al., 2017). This most likely involves specific protein reorganization into large protein complexes masking specific epitopes but could also suggest structural protein remodeling due through specific interactions or through lipid content remodeling (Sailaja et al., 2004; Ovchynnikova et al., 2017). Unfortunately, not much is known about how volume loss and discoid shaping are manifesting during differentiation, and what is known is mainly obtained from animals with reticulocytosis caused by stress erythropoiesis. Generalizing, there are three major events occurring in this time window: volume control, membrane remodeling and vesicularization (Figure 2).

\section{Reticulocyte Volume Control}

It has been calculated that the average cell volume of a reticulocyte once egressed from the bone marrow is $115 \mathrm{fL}$ and decreases to

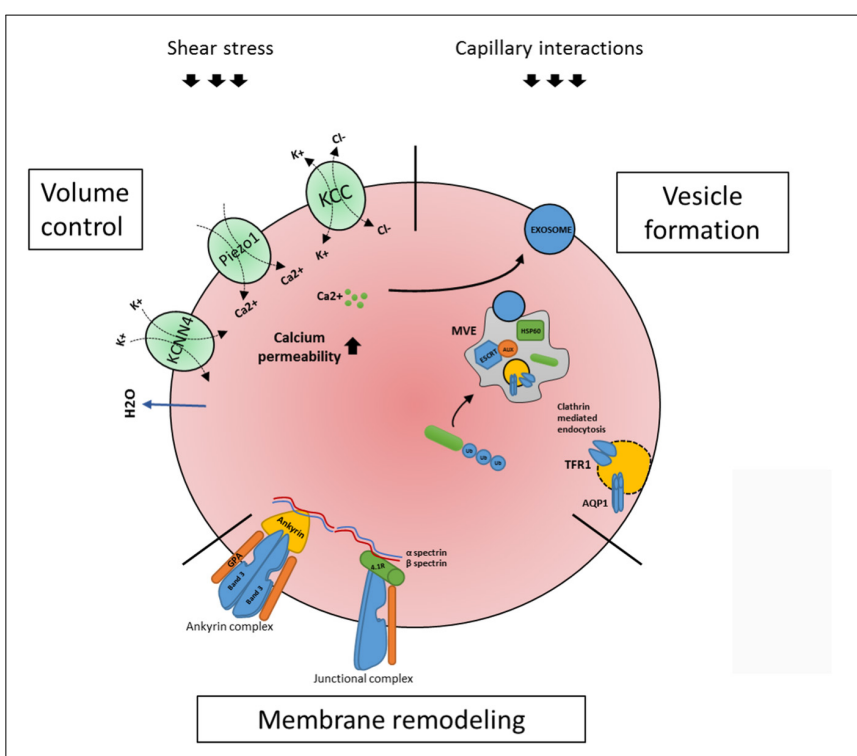

FIGURE 2 | Processes occurring within the maturing circulating reticulocyte. Once enucleated, the newly formed reticulocyte migrates to the peripheral blood where it completes its maturation in a surrounding eliciting external forces, shear stress and capillary/splenic interactions. Three major events occurring are volume control, membrane remodeling and vesicularization. As for volume control, a key role is played by ion channels KCNN4 (or Gardos), Piezo1 and KCC1 (see text). During reticulocyte maturation an active membrane remodeling is also occurring, in which the two main red blood cells complexes, the ankyrin and the junctional complexes (linked through a cytoskeleton network) are involved (see text). Lastly, the reticulocyte makes use of the ESCRT- mediated multi vesicular body (MVB) machinery to expel unwanted proteins. Proteins, e.g., TFR1 and Aquaporin1 are ubiquitinated and routed to the MVB where the ESCRT complex (in particular its associated protein Alix and Hsp60) contributes in assembling the MVB; this process will result in exosome releasing, which is also described to be triggered by calcium influx (see text). All three processes are mechanistically linked (see text) and need to occur in order for a reticulocyte to mature to an erythrocyte. 
$85 \mathrm{fL}$ in mature erythrocytes, while the hemoglobin concentration (CHC) is increasing from 27 to $33 \mathrm{~g} / \mathrm{dL}$ (Gallagher, 2017). Reticulocyte volume loss can be attributed to two processes, (i) through loss of membranes and intracellular remnants due to exosome/vesicle formation/shedding and (ii) through actions of transporters that regulate the cation/anion and water content and thereby cell volume. The contribution of each process to the eventual $20 \%$ loss of cell volume is not known. The potassium chloride cotransporter (KCC) is important in these processes. When KCC is activated, the cell loses potassium, chloride and water leading to cell volume loss. It was demonstrated that KCC activity decreases during reticulocyte maturation (Canessa et al., 1987; Bize et al., 2003; Quarmyne et al., 2011). It was also proven that Sickle Cell reticulocytes have an altered regulation of KCC activity, possibly being the cause of Sickle Cells dehydration. In conjunction with KCC, the mechanosensitive channel Piezo1 plays a role in volume regulation (Bagriantsev et al., 2014). When activated, Piezol causes $\mathrm{Ca}^{2+}$ to enter the cell, leading to the activation of the Gardos-channel associated with a change on $\mathrm{K}+$ and $\mathrm{Cl}-$ influx and water loss, essential events that allow the red blood cell to narrow through the blood capillaries (Fermo et al., 2017). Presently, numerous gain of function mutations in the mechanosensor Piezol have been found that cause the most common form of hereditary stomatocytosis namely hereditary xerocytosis (Zarychanski et al., 2012; Albuisson et al., 2013; Andolfo et al., 2013; Da Costa et al., 2013; Archer et al., 2014; Beneteau et al., 2014; Sandberg et al., 2014). Interestingly, a Piezo channel agonist independent of the mechanosensitive mode of activation has been found, YODA1, that selectively activates the Piezo channel function. This induces calcium influx and erythrocyte dehydration confirming its the role of Piezo-1 in volume control (Cahalan et al., 2015; Syeda et al., 2015). Calcium permeability in reticulocytes is significantly increased compared to erythrocytes. Healthy reticulocytes are 43 times more permeable to $\mathrm{Ca}^{2+}$ compared to mature erythrocytes (Wiley and Shaller, 1977), which may be linked to mechanosensing, through, e.g., Piezol. Indeed, inhibiting $N$-methyl-D-aspartate-induced calcium influx during erythroid maturation results in defective differentiation (Makhro et al., 2013). In addition, increased intracellular calcium levels due to secondary calcium-dependent phosphorylation processes have been observed in reticulocytes and may possibly link to specific phosphorylation of junctional and ankyrin complex proteins necessary for erythrocyte structural integrity (de Haro et al., 1985; Liu et al., 2010). Not all signal transduction that results in calcium influx in erythrocytes is functional in reticulocytes indicating an interesting signal specificity. For instance, lysophosphatidic acid (LPA) stimulation of RBCs is known to increase $\mathrm{Ca}^{2+}$ influx in erythrocytes (Yang et al., 2000), however, reticulocytes lack a $\mathrm{Ca}^{2+}$ response to LPA stimulation (Wang et al., 2013). Interestingly, $\mathrm{Ca}^{2+}$ ionophore-induced laminin association in SCD erythrocytes was not observed in reticulocytes (Burnett et al., 2004). It is known that increased $\mathrm{Ca}^{2+}$ flux induces release of vesicles in erythrocytes, which can contribute to the vast membrane loss during reticulocyte maturation (Kostova et al., 2015). How calcium signaling contributes to reticulocyte maturation will need to be further investigated, but reticulocytes express several surface molecules that induce $\mathrm{Ca}^{2+}$ fluxes.

\section{Extracellular Factors Involved in Reticulocyte Maturation}

Exiting the bone marrow, reticulocytes end up in a complex environment where their fate and development may be determined by a plethora of factors such as interactions with other blood components, endothelial cells, red pulp macrophages of the spleen, macrophages in liver and physical forces such as shear stress and osmolarity changes. Whilst the role of splenic and liver interactions in the development of reticulocyte was extensively studied (Yuditskaya et al., 2010; Klei et al., 2017), the influence of the shear stress forces and capillary interactions remains to date unclear. Reticulocytes share characteristics with erythrocytes of sickle cell disease (SCD) patients. Therefore, the physiology of sickle cells and their interaction with endothelium can shed some light on the fate of healthy reticulocytes in the blood stream. Patients with SCD are prone to develop painful vaso-occlusive crisis, which is characterized by abnormal interaction between red cells, leukocytes and endothelium and can lead to aggregate formation (Manodori et al., 1998). Reticulocyte-specific maintenance expression of adhesion proteins that may facilitate interaction with the endothelium. Among those proteins are $\alpha_{4} \beta_{1}$ integrin which is widely expressed on reticulocytes and interacts with VCAM-1, CD47 which binds to thrombospondin and Lu/BCAM which interacts with laminin (Gee and Platt, 1995; Udani et al., 1998). Hillery et al. (1996) showed that during reticulocytosis an increase, albeit modest, in thrombospondin association was observed, which may indicate increased endothelial interaction of reticulocytes. Although interactions with the endothelium would generally be considered as unwanted, it is unknown why reticulocytes still express specific receptors that could facilitate these interactions and if a so whether biological relevance can be found concerning endothelial interactions. Sickle cells display a higher activation status of Lutheran while healthy reticulocytes display higher expression of Lu/BCAM compared to erythrocytes, while the activation status of Lutheran in reticulocytes is less clear (Malleret et al., 2013). Binding of sickle cells to laminin is mediated via stimulation of $\beta$-adrenergic receptor and subsequent activation of $G_{\alpha s}$, which stimulates adenylyl cyclase. This enzyme induces conversion of ATP to CAMP, which activates PKA. This kinase mediates Lu/BCAM adhesion to laminin via yet unknown targets (Hines et al., 2003). Another molecule which is upregulated on sickle cells as well as on healthy reticulocytes is CD47, which binds to soluble and surface associated thrombospondin. Brittain et al. (2001) demonstrated increased affinity of sickle cells to thrombospondin upon shear stress application via activation of $\mathrm{G}_{1}$ tyrosine kinase pathway. The relations between maturing red blood cells and macrophages of spleen and liver is important. It is proposed that macrophages of red pulp take part in "polishing" of the red cell membrane by removing excessive membranes and exosomes [reviewed by (Klei et al., 2017)]. Indicative of this "polishing" role is the presence of exosomes and inclusions such as Howell-Jolly bodies in splenectomized 
patients, whereas in healthy patients less than $2 \%$ of red blood cells have visible inclusions. Splenectomized patients show an increase in reticulocyte numbers. It has been speculated that this is due to delayed maturation and not by increased erythroid flux (De Haan et al., 1988). General reticulocyte parameters like morphological changes or volume loss are, however, not affected upon splenectomy indicating that spleen macrophages are not essential for these maturation parameters. Despite the specific quality control functions by splenic macrophages, reticulocyte maturation proceeds as normal in splenectomized patient indicating that reticulocyte maturation is partly intrinsic, or dependent on passage through other erythroid-regulating organs such as the liver, and may be promoted by other processes such as shear stress-induced signaling or endothelial interactions.

\section{Membrane and Cytoskeleton Remodeling During Reticulocyte Maturation}

Reticulocyte maturation is accompanied not only by a loss of cytosolic organelles, but also by an intense membrane remodeling. In red blood cells, two major membrane complexes are found: the ankyrin complex and the junctional (or 4.1 based) complex. These complexes are linked through a fine cytoskeletal network which involves spectrin as the main constituent. The anion transporter protein Band 3 (Anion Exchanger 1) plays a key role, as it is the main component of both complexes and anchors them to the cytoskeleton (Mohandas and Gallagher, 2008; van den Akker et al., 2010c). The cytoskeletal network comprises proteins like $\alpha$-spectrin, $\beta$-spectrin, actin, protein $4.1 \mathrm{R}$, ankyrin $\mathrm{R}$, protein 4.2, p55, adducin, dematin, tropomyosin, and tropomodulin (Liu et al., 2011). Ankyrin deficiency causes a disruption of the membrane network, including the incapacity of Band 3 to form tetrameric complex and degradation of protein 4.2 , together with loss of reticulocytes protein due to increased sorting of these proteins in the pyrenocyte (Satchwell et al., 2016). Some of these proteins are also lost during normal reticulocyte maturation, such as cytosolic actin and tubulin while some noncytoskeletal proteins including GLUT4, $\mathrm{Na}^{+} \mathrm{K}^{+}$ATPase, GPA and CD47 are only reduced (Liu et al., 2010). The reduction involves also the membrane protein Glycophorin A (GPA), although in our recent study we showed that during reticulocyte maturation GPA expression is only changing slightly compared to mature erythrocytes (Ovchynnikova et al., 2017). Band 3, Rh, RhAG, GPC, and XK are increased, most probably due to a loss of the membrane surface (Liu et al., 2010). The mechanisms behind the differential change in expression of the membrane proteins are nowadays still unknown. The loss of tubulin and actin has been proved to be mediated by the ubiquitin-proteasome system (Liu et al., 2010). Phosphorylation of certain proteins could play a role. Indeed, phosphorylation of 4.1 protein is significantly higher in reticulocytes compared to erythrocytes (Liu et al., 2010). Phosphorylation of protein 4.1 regulates the strength of the spectrin-p55-4.1R ternary complex, and increased phosphorylation in reticulocytes weakens the association of these proteins in reticulocytes compared to erythrocytes (Manno et al., 2005). Decreasing 4.1 phosphorylation during reticulocyte maturation will strengthen the junctional complex and regulates the mechanical stress mature erythrocytes can endure. Interestingly, a spectrin fragment mimicking a $\beta$ spectrin region involved in the ternary complex formation is incorporated more easily in reticulocytes than erythrocytes, resulting in a more unstable junctional complex in reticulocytes (Manno et al., 2005). Interestingly other proteins comprising the junctional complex, GPC, XK, and Kell, are more extractable upon detergent treatment underscoring the weakened link of these membrane proteins to the underlying spectrin cytoskeleton. In contrast, proteins within the ankyrin complex remain bound to cytoskeleton (band 3, Rh, RhAG, and GPA), suggesting that during reticulocyte maturation the latter complex is already formed, while the former is still remodeling, eventually contributing to a more stable cell with an higher tolerance toward shear stress. Presently little is known about the regulation of these complexes through phosphorylation in reticulocytes. The assembly of these complexes during erythropoiesis is critical to the eventual stability of in vitro produced erythrocytes. Indeed, due to the optimization of in vitro human and mouse erythroblast culture systems, we are beginning to understand the assembly of these large protein complexes during erythropoiesis (Tchernia et al., 1981; Hanspal et al., 1992, 1998a; van den Akker et al., 2010b; Satchwell et al., 2011; Trakarnsanga et al., 2017).

\section{Protein Removal During Reticulocyte Maturation Through Exosome Shedding}

Another example of membrane remodeling involves the transferrin receptor TFR1 (also referred as CD71). In general, iron-loaded transferrin binds to TFR1 and internalizes via clathrin-mediated endocytosis. In the endosome the transferrinreceptor is stripped of the iron and transferrin-receptor complex returns to the membrane, where TFR1 release apo-transferrin and with that finishes the cycle (Hentze et al., 2010). But how is TFR1 lost in reticulocytes? As heme production and transcription of globins is shut down due to mitochondrial loss and enucleation, respectively, there is no need to import the oxidative-damage-inducing iron anymore. Thus, the nascent reticulocyte has incorporated all the iron needed, and the transferrin receptor must be removed, in order to prevent overloading of iron. This involves the switching from recycling of the receptor to the encapsulation into vesicles that will be removed. It is known since 1983 that the transferrin receptor sheds into vesicles. In fact, the term exosome or vesicle release has been shown for the first time in reticulocytes (Johnstone et al., 1987), but it was only later that these vesicles were defined as exosomes. This receptor is sorted through the multivesicular endosomes (MVEs) pathway, that terminates with the incorporation of TFR1 in a new formed vesicle that is subsequently fused with plasma membrane in order for the content to be released into the extracellular medium (Pan et al., 1985). About the molecular players involved in this process, it has been shown that hsp60 and the ESCRT associated protein Alix co-localize with TFR1 in reticulocytes exosomes, confirming the involvement of the endosomal - vesicular pathway in exosomes formation (Geminard et al., 2004). Interestingly, CD71 shedding 
can also be regulated in $\mathrm{Ca}^{2+}$ dependent manner and activated by extracellular transferrin (Savina et al., 2003). Among proteins that are cleared from reticulocytes through formation of vesicles is Aquaporin 1 (AQP1). This water channel is responsible for keeping a proper plasma membrane tonicity, in response to different osmotic perturbations. It co-localizes with TFR1 in the plasma membrane and in reticulocytes endosomal compartments (Blanc et al., 2009). Together with the knowledge that the loss of aquaporin-1 has been described as a prototype example of degradation through exosomes, recent data show that AQP1 is expressed at higher levels in adult red blood cell compared to cord blood cells, as well as in adult reticulocytes compared to cord reticulocytes. Such a difference possibly reflects a different gas exchange regulation in adult and neonatal red blood cells, although this remains to be confirmed (Schutte et al., 2016). Together with TFR1 and aquaporin 1, multiple proteins need to be disposed from the plasma membrane or the cytosol during reticulocyte maturation, presumably and sensibly from an evolutionary point of view via the same mechanism. The major process involves different routes of targeting proteins to multivesicular bodies (MVB), including the lipid domain inclusion, cytosolic inclusion and lectin mediated inclusion, targeting ubiquitinated, HSC/HSP bounds proteins and glycosylated proteins to MVBs (Guinez et al., 2007; Carayon et al., 2011). The ESCRT (Endosomal Sorting Complex Required for Transport) machinery comprises four complexes: ESCRT 0, I, II, III that are involved in MVB formation. Briefly, in the endosomal lumen, ESCRT 0, which has multiple ubiquitin binding domains, binds the ubiquitinated cargo (i.e., proteins destined to be included in the vesicles) and engages the other ESCRT subunits, while facilitating interactions with clathrin domains. ESCRT I and II are recruited and cause the deforming and involution of the membrane. The process is terminated by recruitment of ESCRT III by simultaneously pulling the cargo into the invagination and generating the MVB. It is generally believed that ESCRT complexes recognize ubiquitinated membrane proteins that need to be sorted into MVB (Odorizzi et al., 1998; Raiborg and Stenmark, 2009; Hislop and von Zastrow, 2011). In contrast, intracellular proteins may be routed to MVB via HSP70/HSC70 via ill-defined mechanisms. These mechanisms include, (i) HSC70 interacting with the endosomal membrane via electrostatic associations using its C-terminal basic region (Sahu et al., 2011), (ii) interactions with the ESCRT complex again via ubiquitin-modified targets (Dajani et al., 2001) or (iii) through ubiquitination of hsc70 itself (Pridgeon et al., 2009). Hsc70-dependent microautophagic processes are thus probably linked to MVB targeting and removal of unwanted proteins. Recently, UBE2O, an E2-E3 hybrid enzyme, which acts both as ubiquitin-conjugating enzyme and ubiquitin ligase has been found to play a key role in erythroid proteome remodeling among which ribosome elimination (Nguyen et al., 2017). A further link between autophagy and plasma-membrane vesicles was found with the co-localization of glycophorin A and the autophagy protein LC3 on intracellular reticulocyte vesicles (Griffiths et al., 2012). Griffiths et al propose that the final remnants of the plasma membrane are removed via an autophagosome/endosome hybrid compartment. Exosome composition indeed changes in protein composition during maturation (Carayon et al., 2011). Whether these vesicles are different entities or similar remains to be investigated as in other cell types the autophagosome can fuse with endocytic structures such as MVBs to generate an amphisome (Berg et al., 1998). Furthermore, efficient autophagic degradation requires functional MVBs and their fusion is again calcium dependent (Fader and Colombo, 2009). Normally, besides exosome release, these vesicle bodies are destined to fuse with the lysosome, causing the degradation of specific proteins (Saksena et al., 2007). However, in maturing reticulocytes these vesicles are exclusively re-routed to a secretory pathway (Pan et al., 1985; Blanc et al., 2009). The mechanisms and in particular the pathways involved in the formation and fusion of the vesicles with the membrane and consequential secretion are not yet fully understood. In the erythroleukemia cell line K562, exosome secretion is caused by an intracellular $\mathrm{Ca}^{2+}$ influx (Savina et al., 2003). Indeed, significant vesicle formation can be induced upon treatment of erythrocytes with the calcium ionophore ionomycin or through PKC activation (Kostova et al., 2015; Nguyen et al., 2016). Moreover, docking and fusion of MVB to the plasma membrane is regulated by calcium dependent small GTPase Rab11 (Savina et al., 2005). Of note, Rab11 has been shown to associate with the pericentriolar recycling endosome, as well as being involved in the regulation of transferrin recycling in the endosome (Ullrich et al., 1996). It is tempting to speculate that during reticulocyte maturation, routing of non-wanted proteins utilizes the same mechanism through which TFR1 is removed. The role of calcium signaling in MVB formation and fusion as well as the increased permeability of reticulocyte to calcium suggest a prominent but ill-characterized role for calcium signaling during reticulocyte formation. The formation, regulation and contents of MVB during reticulocyte maturation requires more attention as (i) it may provide key improvement to the in vitro culture of mature erythrocytes rather than the reticulocytes that are currently the end-stage of most culture protocols and (ii) specific pathologies may already manifest and initiate in the reticulocyte stage due to malfunctions within the sorting/secretory machinery. For instance, in dominant inherited beta-thalassemia's, a heterozygous mutation in the beta globin chain results in unstable hemoglobins and rapid degradation of the beta chains, which may overload the available chaperone/sorting system resulting in additional secondary defects. In addition, an array of erythrocyte diseases is characterized by aberrant expression of membrane proteins that are normally completely or partially removed during erythropoiesis (e.g., BCAM, LW or CD44). However, specificity for over-expression of a small selection of membrane proteins is not easy to explain via the general mechanism of MVBmediated protein removal. Although lists of proteins identified in reticulocyte exosomes have been published (Carayon et al., 2011), more in-depth research into the extruded but also the intracellular vesicles bodies may uncover much needed insight into the cargo and may identify crucial proteins that play a role in the formation and secretion machinery. The fate of exosomes is interesting from a signaling and immunogenic point of view. The membrane of reticulocyte exosomes contains $20 \%$ 
exposed Phosphatidylserine (PS) on the outer leaflet, which is a potent phagocytic trigger for many cells including cells that are in close contact with reticulocytes, e.g., endothelial cells, macrophages and neutrophils (Vidal et al., 1989). This provides a safe clearance mechanism; however, these vesicles may also function as conveyors of specific signals upon uptake by target cells. Research on this topic and specifically concerning reticulocyte exosomes is lacking.

\section{CONCLUSION}

In the bone marrow erythropoiesis progresses until the enucleated reticulocyte stage, after which the reticulocytes are released into the circulation where final maturation occurs. Is there an evolutionary benefit for this maturation to occur in the circulation and not within the bone marrow? Early reticulocytes seem non-optimally adapted to the shear stress within the circulation and display lower deformability. Despite this, it also becomes increasingly clear that reticulocyte maturation is an interplay between intrinsic processes and extrinsic processes, including exosome formation, interactions with splenic and liver cells (e.g., macrophages) and circulation-induced shear forces. Interestingly, erythroid culture protocols are mainly driven by the intrinsic ability of erythroblasts to differentiate into reticulocytes but fail to produce fully biconcave erythrocytes, stressing that specific maturation cues are missing. Although, these missing signals may partly originate from the bone marrow niche, it is surprising that pure $>95 \%$ enucleated reticulocytes can be cultured without this support (Miharada et al., 2006; van den Akker et al., 2010a; Giarratana et al., 2011). Failure to progress from reticulocytes to fully biconcave erythrocytes thus suggests a lack of signals that may be partly independent and dependent of the bone marrow niche. Of note, also stromal cocultures (MS5 or OP9) do not completely result in reticulocyte maturation to erythrocytes (Giarratana et al., 2005; Lu et al., 2008). Indeed, a recent study published a characterization of the secretory proteins from $\mathrm{OP} 9$, and such studies may eventually

\section{REFERENCES}

Albuisson, J., Murthy, S. E., Bandell, M., Coste, B., Louis-Dit-Picard, H., and Mathur, J. (2013). Dehydrated hereditary stomatocytosis linked to gain-offunction mutations in mechanically activated PIEZO1 ion channels. Nat. Commun. 4:1884. doi: 10.1038/ncomms2899

Alkindi, S., AlMahrooqi, S., AlHinai, S., AlMarhoobi, A., Al-Hosni, S., Daar, S., et al. (2017). Alloimmunization in patients with sickle cell disease and thalassemia: experience of a single centre in oman. Mediterr. J. Hematol. Infect. Dis. 9:e2017013. doi: 10.4084/MJHID.2017.013

Andolfo, I., Alper, S. L., Delaunay, J., Auriemma, C., Russo, R., and Asci, R. (2013). Missense mutations in the ABCB6 transporter cause dominant familial pseudohyperkalemia. Am. J. Hematol. 88, 66-72. doi: 10.1002/ajh. 23357

Angelillo-Scherrer, A., Burnier, L., Lambrechts, D., Fish, R. J., Tjwa, M., and Plaisance, S. (2008). Role of Gas6 in erythropoiesis and anemia in mice. J. Clin. Invest. 118, 583-596. doi: 10.1172/JCI30375

Archer, N. M., Shmukler, B. E., Andolfo, I., Vandorpe, D. H., Gnanasambandam, R., and Higgins, J. M. (2014). Hereditary xerocytosis revisited. Am. J. Hematol. 89, 1142-1146. doi: 10.1002/ajh.23799 point to specific factors to will further facilitating erythropoiesis and possibly reticulocyte maturation (Trakarnsanga et al., 2018). One such extrinsic signal may be transport/exchange regulation of volume control upon circulation-induced shear stress to facilitate reticulocyte maturation. However, more research must be performed dissecting the contribution and connections between intrinsic processes and extrinsic factors to this maturation. Even prior to this, the field is currently still assessing the identity/nature of these external factors and their concomitant erythrocyte "signal transducer" counterparts before characterization and optimization can begin. For instance, the connection between exosome formation, cargo selection (e.g., ubiquitination) and cation/anion permeability/conductance is interesting to pursue. With the aid of novel techniques to separate and discriminate the various reticulocyte maturation stages and the progressive use of lower cell numbers in -omic approaches will facilitate this research. Future erythroid culture protocols will need to incorporate the regulation (activation) of these processes to ensure complete differentiation to fully biconcave erythrocytes. The promise of in vitro cultured patient catered personalized transfusion products as well as erythrocytes carrying specific cargo for therapeutic purposes are potent drivers that justify research into this last elusive step of erythropoiesis.

\section{AUTHOR CONTRIBUTIONS}

$\mathrm{EO}, \mathrm{FA}, \mathrm{MvL}$, and EA wrote the manuscript. The manuscript was critically revised by all authors.

\section{FUNDING}

This study was supported by funding from Sanquin (PPOC: 11035) (MvL, EA, and EO), the European Union (FA H2020-MSCA ITN-2015, grant agreement N.675115), "RELEVANCE" and the Landsteiner Foundation (EA, LSBR1141).

Bagriantsev, S. N., Gracheva, E. O., and Gallagher, P. G. (2014). Piezo proteins: regulators of mechanosensation and other cellular processes. J. Biol. Chem. 289, 31673-31681. doi: 10.1074/jbc.R114.612697

Barr, F. A., and Gruneberg, U. (2007). Cytokinesis: placing and making the final cut. Cell 131, 847-860. doi: 10.1016/j.cell.2007.11.011

Bassnett, S. (1997). Fiber cell denucleation in the primate lens. Invest. Ophthalmol. Vis. Sci. 38, 1678-1687.

Belay, E., Hayes, B. J., Blau, C. A., and Torok-Storb, B. (2017). Human cord blood and bone marrow CD34+ cells generate macrophages that support erythroid islands. PLoS One 12:e0171096. doi: 10.1371/journal.pone.0171096

Benedetto, D., Rao, C. M., Cefalu, C., Aguglia, D. O., Cattadori, G., and D’Ascola, D. G. (2015). Effects of blood transfusion on exercise capacity in thalassemia major patients. PLoS One 10:e0127553. doi: 10.1371/journal.pone.0127553

Beneteau, C., Thierry, G., Blesson, S., Le Vaillant, C., Picard, V., and Bene, M. C. (2014). Recurrent mutation in the PIEZO1 gene in two families of hereditary xerocytosis with fetal hydrops. Clin. Genet. 85, 293-295. doi: 10.1111/cge.12147

Berg, T. O., Fengsrud, M., Stromhaug, P. E., Berg, T., and Seglen, P. O. (1998). Isolation and characterization of rat liver amphisomes. Evidence for fusion of autophagosomes with both early and late endosomes. J. Biol. Chem. 273, 21883-21892. doi: 10.1074/jbc.273.34.21883 
Bessis, M. (1958). Erythroblastic island, functional unity of bone marrow. Rev. Hematol. 13, 8-11.

Bessis, M. C., and Breton-Gorius, J. (1962). Iron metabolism in the bone marrow as seen by electron microscopy: a critical review. Blood 19, 635-663.

Bize, I., Taher, S., and Brugnara, C. (2003). Regulation of K-Cl cotransport during reticulocyte maturation and erythrocyte aging in normal and sickle erythrocytes. Am. J. Physiol. Cell Physiol. 285, C31-C38. doi: 10.1152/ajpcell. 00447.2002

Blanc, L., Liu, J., Vidal, M., Chasis, J. A., An, X., and Mohandas, N. (2009). The water channel aquaporin-1 partitions into exosomes during reticulocyte maturation: implication for the regulation of cell volume. Blood 114, 3928-3934. doi: 10.1182/blood-2009-06-230086

Bohmer, R. M. (2004). IL-3-dependent early erythropoiesis is stimulated by autocrine transforming growth factor beta. Stem Cells 22, 216-224. doi: 10.1634/ stemcells.22-2-216

Brittain, J. E., Mlinar, K. J., Anderson, C. S., Orringer, E. P., and Parise, L. V. (2001). Integrin-associated protein is an adhesion receptor on sickle red blood cells for immobilized thrombospondin. Blood 97, 2159-2164. doi: 10.1182/blood.V97.7. 2159

Bruce, L. J. (2008). Red cell membrane transport abnormalities. Curr. Opin. Hematol. 15, 184-190. doi: 10.1097/MOH.0b013e3282f97b0a

Bruce, L. J., Guizouarn, H., Burton, N. M., Gabillat, N., Poole, J., and Flatt, J. F. (2009). The monovalent cation leak in overhydrated stomatocytic red blood cells results from amino acid substitutions in the Rh-associated glycoprotein. Blood 113, 1350-1357. doi: 10.1182/blood-2008-07-171140

Burnett, S. H., Kershen, E. J., Zhang, J., Zeng, L., Straley, S. C., and Kaplan, A. M. (2004). Conditional macrophage ablation in transgenic mice expressing a Fas-based suicide gene. J. Leukoc. Biol. 75, 612-623. doi: 10.1189/jlb.0903442

Cahalan, S. M., Lukacs, V., Ranade, S. S., Chien, S., Bandell, M., and Patapoutian, A. (2015). Piezo1 links mechanical forces to red blood cell volume. eLife 4:e07370 doi: $10.7554 /$ eLife.07370

Campbell-Lee, S. A., and Kittles, R. A. (2014). Red blood cell alloimmunization in sickle cell disease: listen to your ancestors. Transfus. Med. Hemother. 41, 431-435. doi: 10.1159/000369513

Canessa, M., Fabry, M. E., Blumenfeld, N., and Nagel, R. L. (1987). Volumestimulated, $\mathrm{Cl}$-dependent $\mathrm{K}+$ efflux is highly expressed in young human red cells containing normal hemoglobin or HbS. J. Membr. Biol. 97, 97-105. doi: 10.1007/BF01869416

Carayon, K., Chaoui, K., Ronzier, E., Lazar, I., Bertrand-Michel, J., and Roques, V. (2011). Proteolipidic composition of exosomes changes during reticulocyte maturation. J. Biol. Chem. 286, 34426-34439. doi: 10.1074/jbc.M111.25 7444

Carlile, G. W., Smith, D. H., and Wiedmann, M. (2004). Caspase-3 has a nonapoptotic function in erythroid maturation. Blood 103, 4310-4316. doi: 10.1182/blood-2003-09-3362

Chasis, J. A., Coulombel, L., Conboy, J., McGee, S., Andrews, K., and Kan, Y. W. (1993). Differentiation-associated switches in protein 4.1 expression. Synthesis of multiple structural isoforms during normal human erythropoiesis. J. Clin. Invest. 91, 329-338. doi: 10.1172/JCI116189

Chasis, J. A., Prenant, M., Leung, A., and Mohandas, N. (1989). Membrane assembly and remodeling during reticulocyte maturation. Blood 74, 1112-1120.

Cherif-Zahar, B., Raynal, V., Gane, P., Mattei, M. G., Bailly, P., and Gibbs, B. (1996). Candidate gene acting as a suppressor of the RH locus in most cases of Rh-deficiency. Nat. Genet. 12, 168-173. doi: 10.1038/ng0296-168

Choi, J. W., and Pai, S. H. (2001). Reticulocyte subpopulations and reticulocyte maturity index (RMI) rise as body iron status falls. Am. J. Hematol. 67, 130-135. doi: 10.1002/ajh.1091

Chow, A., Lucas, D., Hidalgo, A., Mendez-Ferrer, S., Hashimoto, D., and Scheiermann, C. (2011). Bone marrow $\mathrm{CD}_{169^{+}}$macrophages promote the retention of hematopoietic stem and progenitor cells in the mesenchymal stem cell niche. J. Exp. Med. 208, 261-271. doi: 10.1084/jem.20101688

Connor, W. E., Lin, D. S., Thomas, G., Ey, F., DeLoughery, T., and Zhu, N. (1997). Abnormal phospholipid molecular species of erythrocytes in sickle cell anemia. J. Lipid Res. 38, 2516-2528.

Crossan, G. P., van der Weyden, L., Rosado, I. V., Langevin, F., Gaillard, P. H., and McIntyre, R. E. (2011). Disruption of mouse Slx4, a regulator of structurespecific nucleases, phenocopies Fanconi Anemia. Nat. Genet. 43, 147-152. doi: $10.1038 /$ ng.752
Da Costa, L., Galimand, J., Fenneteau, O., and Mohandas, N. (2013). Hereditary spherocytosis, elliptocytosis, and other red cell membrane disorders. Blood Rev. 27, 167-178. doi: 10.1016/j.blre.2013.04.003

Dajani, R., Fraser, E., Roe, S. M., Young, N., Good, V., and Dale, T. C. (2001). Crystal structure of glycogen synthase kinase 3 beta: structural basis for phosphate-primed substrate specificity and autoinhibition. Cell 105, 721-732. doi: 10.1016/S0092-8674(01)00374-9

Davis, B. H., Ornvold, K., and Bigelow, N. C. (1995). Flow cytometric reticulocyte maturity index: a useful laboratory parameter of erythropoietic activity in anemia. Cytometry 22, 35-39. doi: 10.1002/cyto.990220107

De Haan, L. D., Werre, J. M., Ruben, A. M., Huls, A. H., de Gier, J., and Staal, G. E. (1988). Reticulocyte crisis after splenectomy: evidence for delayed red cell maturation? Eur. J. Haematol. 41, 74-79. doi: 10.1111/j.1600-0609.1988. tb00872.x

de Haro, C., de Herreros, A. G., and Ochoa, S. (1985). Protein phosphorylation and translational control in reticulocytes: activation of the heme-controlled translational inhibitor by calcium ions and phospholipid. Curr. Top. Cell. Regul. 27, 63-81. doi: 10.1016/B978-0-12-152827-0.50013-X

Douay, L., and Andreu, G. (2007). Ex vivo production of human red blood cells from hematopoietic stem cells: what is the future in transfusion? Transfus. Med. Rev. 21, 91-100. doi: 10.1016/j.tmrv.2006.11.004

Fader, C. M., and Colombo, M. I. (2009). Autophagy and multivesicular bodies: two closely related partners. Cell Death Differ. 16, 70-78. doi: 10.1038/cdd.2008.168

Fermo, E., Bogdanova, A., Petkova-Kirova, P., Zaninoni, A., Marcello, A. P., and Makhro, A. (2017). 'Gardos Channelopathy': a variant of hereditary Stomatocytosis with complex molecular regulation. Sci. Rep. 7:1744. doi: 10. 1038/s41598-017-01591-w

Focosi, D., and Amabile, G. (2017). Induced pluripotent stem cell-derived red blood cells and platelet concentrates: from bench to bedside. Cells 7:E2. doi: 10.3390/cells7010002

Fujimi, A., Matsunaga, T., Kobune, M., Kawano, Y., Nagaya, T., Tanaka, I., et al. (2008). Ex vivo large-scale generation of human red blood cells from cord blood $\mathrm{CD}_{34}{ }^{+}$cells by co-culturing with macrophages. Int. J. Hematol. 87, 339-350. doi: 10.1007/s12185-008-0062-y

Gallagher, P. G. (2013). Abnormalities of the erythrocyte membrane. Pediatr. Clin. North Am. 60, 1349-1362. doi: 10.1016/j.pcl.2013.09.001

Gallagher, P. G. (2017). Disorders of erythrocyte hydration. Blood 130, 2699-2708. doi: 10.1182/blood-2017-04-590810

Gautier, E. F., Ducamp, S., Leduc, M., Salnot, V., Guillonneau, F., and Dussiot, M. (2016). Comprehensive proteomic analysis of human erythropoiesis. Cell Rep. 16, 1470-1484. doi: 10.1016/j.celrep.2016.06.085

Gee, B. E., and Platt, O. S. (1995). Sickle reticulocytes adhere to VCAM-1. Blood 85, $268-274$.

Geminard, C., De Gassart, A., Blanc, L., and Vidal, M. (2004). Degradation of AP2 during reticulocyte maturation enhances binding of hsc70 and Alix to a common site on TFR for sorting into exosomes. Traffic 5, 181-193. doi: 10.1111/j.1600-0854.2004.0167.x

Giarratana, M. C., Kobari, L., Lapillonne, H., Chalmers, D., Kiger, L., and Cynober, T. (2005). Ex vivo generation of fully mature human red blood cells from hematopoietic stem cells. Nat. Biotechnol. 23, 69-74. doi: 10.1038/nbt 1047

Giarratana, M. C., Rouard, H., Dumont, A., Kiger, L., Safeukui, I., and Le Pennec, P. Y. (2011). Proof of principle for transfusion of in vitro-generated red blood cells. Blood 118, 5071-5079. doi: 10.1182/blood-2011-06-362038

Goodnough, L. T., and Murphy, M. F. (2014). Do liberal blood transfusions cause more harm than good? BMJ 349:g6897. doi: 10.1136/bmj.g6897

Griffiths, R. E., Kupzig, S., Cogan, N., Mankelow, T. J., Betin, V. M., and Trakarnsanga, K. (2012). Maturing reticulocytes internalize plasma membrane in glycophorin A-containing vesicles that fuse with autophagosomes before exocytosis. Blood 119, 6296-6306. doi: 10.1182/blood-2011-09-376475

Gromley, A., Yeaman, C., Rosa, J., Redick, S., Chen, C. T., and Mirabelle, S. (2005). Centriolin anchoring of exocyst and SNARE complexes at the midbody is required for secretory-vesicle-mediated abscission. Cell 123, 75-87. doi: 10. 1016/j.cell.2005.07.027

Gronowicz, G., Swift, H., and Steck, T. L. (1984). Maturation of the reticulocyte in vitro. J. Cell Sci. 71, 177-197.

Guinez, C., Mir, A. M., Leroy, Y., Cacan, R., Michalski, J. C., and Lefebvre, T. (2007). Hsp70-GlcNAc-binding activity is released by stress, proteasome 
inhibition, and protein misfolding. Biochem. Biophys. Res. Commun. 361, 414420. doi: 10.1016/j.bbrc.2007.07.020

Hanspal, M., Golan, D. E., Smockova, Y., Yi, S. J., Cho, M. R., and Liu, S. C. (1998a) Temporal synthesis of band 3 oligomers during terminal maturation of mouse erythroblasts. Dimers and tetramers exist in the membrane as preformed stable species. Blood 92, 329-338.

Hanspal, M., Hanspal, J. S., Kalraiya, R., Liu, S. C., Sahr, K. E., and Howard, D. (1992). Asynchronous synthesis of membrane skeletal proteins during terminal maturation of murine erythroblasts. Blood 80, 530-539.

Hanspal, M., Smockova, Y., and Uong, Q. (1998b). Molecular identification and functional characterization of a novel protein that mediates the attachment of erythroblasts to macrophages. Blood 92, 2940-2950.

Heideveld, E., Masiello, F., Marra, M., Esteghamat, F., Yagci, N., and von Lindern, M. (2015). CD14 ${ }^{+}$cells from peripheral blood positively regulate hematopoietic stem and progenitor cell survival resulting in increased erythroid yield. Haematologica 100, 1396-1406. doi: 10.3324/haematol.2015.125492

Heideveld, E., and van den Akker, E. (2017). Digesting the role of bone marrow macrophages on hematopoiesis. Immunobiology 222, 814-822. doi: 10.1016/j. imbio.2016.11.007

Heilmeyer, L., and Westhäuser, R. (1932). Reifungsstadien an überlebenden reticulozyten in vitro und ihre bedeutung für die schaetzung der täglichen haemoglobin-produktion in vivo. Ztschr. Klin. Med. 121, 361-379.

Hentze, M. W., Muckenthaler, M. U., Galy, B., and Camaschella, C. (2010). Two to tango: regulation of Mammalian iron metabolism. Cell 142, 24-38. doi: 10.1016/j.cell.2010.06.028

Hillery, C. A., Du, M. C., Montgomery, R. R., and Scott, J. P. (1996). Increased adhesion of erythrocytes to components of the extracellular matrix: isolation and characterization of a red blood cell lipid that binds thrombospondin and laminin. Blood 87, 4879-4886.

Hines, P. C., Zen, Q., Burney, S. N., Shea, D. A., Ataga, K. I., and Orringer, E. P. (2003). Novel epinephrine and cyclic AMP-mediated activation of BCAM/Ludependent sickle (SS) RBC adhesion. Blood 101, 3281-3287. doi: 10.1182/ blood-2001-12-0289

Hislop, J. N., and von Zastrow, M. (2011). Role of ubiquitination in endocytic trafficking of G-protein-coupled receptors. Traffic 12, 137-148. doi: 10.1111/ j.1600-0854.2010.01121.x

Hom, J., Dulmovits, B. M., Mohandas, N., and Blanc, L. (2015). The erythroblastic island as an emerging paradigm in the anemia of inflammation. Immunol. Res. 63, 75-89. doi: 10.1007/s12026-015-8697-2

Jayapal, S. R., Lee, K. L., Ji, P., Kaldis, P., Lim, B., and Lodish, H. F. (2010). Downregulation of Myc is essential for terminal erythroid maturation. J. Biol. Chem. 285, 40252-40265. doi: 10.1074/jbc.M110.181073

Ji, P., Jayapal, S. R., and Lodish, H. F. (2008). Enucleation of cultured mouse fetal erythroblasts requires Rac GTPases and mDia2. Nat. Cell Biol. 10, 314-321. doi: $10.1038 /$ ncb1693

Ji, P., Yeh, V., Ramirez, T., Murata-Hori, M., and Lodish, H. F. (2010). Histone deacetylase 2 is required for chromatin condensation and subsequent enucleation of cultured mouse fetal erythroblasts. Haematologica 95, 20132021. doi: 10.3324/haematol.2010.029827

Johnstone, R. M., Adam, M., Hammond, J. R., Orr, L., and Turbide, C. (1987) Vesicle formation during reticulocyte maturation. Association of plasma membrane activities with released vesicles (exosomes). J. Biol. Chem. 262, 9412-9420.

Keerthivasan, G., Small, S., Liu, H., Wickrema, A., and Crispino, J. D. (2010). Vesicle trafficking plays a novel role in erythroblast enucleation. Blood 116, 3331-3340. doi: 10.1182/blood-2010-03-277426

Keerthivasan, G., Wickrema, A., and Crispino, J. D. (2011). Erythroblast enucleation. Stem Cells Int. 2011:139851. doi: 10.4061/2011/139851

Kim, P. G., Nakano, H., Das, P. P., Chen, M. J., Rowe, R. G., and Chou, S. S. (2015). Flow-induced protein kinase A-CREB pathway acts via BMP signaling to promote HSC emergence. J. Exp. Med. 212, 633-648. doi: 10.1084/jem. 20141514

Klei, T. R., Meinderts, S. M., van den Berg, T. K., and van Bruggen, R. (2017). From the cradle to the grave: the role of macrophages in erythropoiesis and erythrophagocytosis. Front. Immunol. 8:73. doi: 10.3389/fimmu.2017.00073

Konstantinidis, D. G., Pushkaran, S., Johnson, J. F., Cancelas, J. A., Manganaris, S., and Harris, C. E. (2012). Signaling and cytoskeletal requirements in erythroblast enucleation. Blood 119, 6118-6127. doi: 10.1182/blood-2011-09-379263
Kostova, E. B., Beuger, B. M., Klei, T. R., Halonen, P., Lieftink, C., and Beijersbergen, R. (2015). Identification of signalling cascades involved in red blood cell shrinkage and vesiculation. Biosci. Rep. 35:e00187. doi: 10.1042/ BSR20150019

Kurita, R., Suda, N., Sudo, K., Miharada, K., Hiroyama, T., and Miyoshi, H. (2013). Establishment of immortalized human erythroid progenitor cell lines able to produce enucleated red blood cells. PLoS One 8:e59890. doi: 10.1371/journal. pone. 0059890

Kuypers, F. A., Larkin, S. K., Emeis, J. J., and Allison, A. C. (2007). Interaction of an annexin $\mathrm{V}$ homodimer (Diannexin) with phosphatidylserine on cell surfaces and consequent antithrombotic activity. Thromb. Haemost. 97, 478-486. doi: 10.1160/TH06-08-0436

Lapillonne, H., Kobari, L., Mazurier, C., Tropel, P., Giarratana, M. C., and ZanellaCleon, I. (2010). Red blood cell generation from human induced pluripotent stem cells: perspectives for transfusion medicine. Haematologica 95, 1651-1659. doi: 10.3324/haematol.2010.023556

Leberbauer, C., Boulme, F., Unfried, G., Huber, J., Beug, H., and Mullner, E. W. (2005). Different steroids co-regulate long-term expansion versus terminal differentiation in primary human erythroid progenitors. Blood 105, 85-94. doi: 10.1182/blood-2004-03-1002

Lee, G., Lo, A., Short, S. A., Mankelow, T. J., Spring, F., and Parsons, S. F. (2006). Targeted gene deletion demonstrates that the cell adhesion molecule ICAM-4 is critical for erythroblastic island formation. Blood 108, 2064-2071. doi: 10.1182/blood-2006-03-006759

Lee, J. C., Gimm, J. A., Lo, A. J., Koury, M. J., Krauss, S. W., and Mohandas, N. (2004). Mechanism of protein sorting during erythroblast enucleation: role of cytoskeletal connectivity. Blood 103, 1912-1919. doi: 10.1182/blood-2003-030928

Leimberg, M. J., Prus, E., Konijn, A. M., and Fibach, E. (2008). Macrophages function as a ferritin iron source for cultured human erythroid precursors. J. Cell. Biochem. 103, 1211-1218. doi: 10.1002/jcb.21499

Liu, J., Guo, X., Mohandas, N., Chasis, J. A., and An, X. (2010). Membrane remodeling during reticulocyte maturation. Blood 115, 2021-2027. doi: 10. 1182/blood-2009-08-241182

Liu, J., Mohandas, N., and An, X. (2011). Membrane assembly during erythropoiesis. Curr. Opin. Hematol. 18, 133-138. doi: 10.1097/MOH. 0b013e32834521f3

Lu, S. J., Feng, Q., Park, J. S., Vida, L., Lee, B. S., and Strausbauch, M. (2008). Biologic properties and enucleation of red blood cells from human embryonic stem cells. Blood 112, 4475-4484. doi: 10.1182/blood-2008-05-157198

Magor, G. W., Tallack, M. R., Gillinder, K. R., Bell, C. C., McCallum, N., and Williams, B. (2015). KLF1-null neonates display hydrops fetalis and a deranged erythroid transcriptome. Blood 125, 2405-2417. doi: 10.1182/blood-2014-08590968

Makhro, A., Hanggi, P., Goede, J. S., Wang, J., Bruggemann, A., and Gassmann, M. (2013). N-methyl-D-aspartate receptors in human erythroid precursor cells and in circulating red blood cells contribute to the intracellular calcium regulation. Am. J. Physiol. Cell Physiol. 305, C1123-C1138. doi: 10.1152/ajpcell.00031. 2013

Malleret, B., Xu, F., Mohandas, N., Suwanarusk, R., Chu, C., and Leite, J. A. (2013). Significant biochemical, biophysical and metabolic diversity in circulating human cord blood reticulocytes. PLoS One 8:e76062. doi: 10.1371/journal.pone. 0076062

Manno, S., Takakuwa, Y., and Mohandas, N. (2005). Modulation of erythrocyte membrane mechanical function by protein 4.1 phosphorylation. J. Biol. Chem. 280, 7581-7587. doi: 10.1074/jbc.M410650200

Manodori, A. B., Matsui, N. M., Chen, J. Y., and Embury, S. H. (1998). Enhanced adherence of sickle erythrocytes to thrombin-treated endothelial cells involves interendothelial cell gap formation. Blood 92, 3445-3454.

Mel, H. C., Prenant, M., and Mohandas, N. (1977). Reticulocyte motility and form: studies on maturation and classification. Blood 49, 1001-1009.

Meyron-Holtz, E. G., Vaisman, B., Cabantchik, Z. I., Fibach, E., Rouault, T. A., and Hershko, C. (1999). Regulation of intracellular iron metabolism in human erythroid precursors by internalized extracellular ferritin. Blood 94, 3205-3211.

Migliaccio, A. R. (2010). Erythroblast enucleation. Haematologica 95, 1985-1988. doi: 10.3324/haematol.2010.033225

Migliaccio, G., Di Pietro, R., di Giacomo, V., Di Baldassarre, A., Migliaccio, A. R. and Maccioni, L. (2002). In vitro mass production of human erythroid cells 
from the blood of normal donors and of thalassemic patients. Blood Cells Mol. Dis. 28, 169-180. doi: 10.1006/bcmd.2002.0502

Migliaccio, G., Sanchez, M., Masiello, F., Tirelli, V., Varricchio, L., and Whitsett, C. (2010). Humanized culture medium for clinical expansion of human erythroblasts. Cell Transplant. 19, 453-469. doi: 10.3727/096368909X485049

Miharada, K., Hiroyama, T., Sudo, K., Nagasawa, T., and Nakamura, Y. (2006). Efficient enucleation of erythroblasts differentiated in vitro from hematopoietic stem and progenitor cells. Nat. Biotechnol. 24, 1255-1256. doi: 10.1038/nbt1245

Millot, S., Andrieu, V., Letteron, P., Lyoumi, S., and Hurtado-Nedelec, M. (2010). Erythropoietin stimulates spleen BMP4-dependent stress erythropoiesis and partially corrects anemia in a mouse model of generalized inflammation. Blood 116, 6072-6081. doi: 10.1182/blood-2010-04-281840

Mohandas, N., and Gallagher, P. G. (2008). Red cell membrane: past, present, and future. Blood 112, 3939-3948. doi: 10.1182/blood-2008-07-161166

Mohandas, N., and Prenant, M. (1978). Three-dimensional model of bone marrow. Blood 51, 633-643.

Mordue, K. E., Hawley, B. R., Satchwell, T. J., and Toye, A. M. (2017). CD47 surface stability is sensitive to actin disruption prior to inclusion within the band 3 macrocomplex. Sci. Rep. 7:2246. doi: 10.1038/s41598-017-02356-1

Muzykantov, V. R. (2010). Drug delivery by red blood cells: vascular carriers designed by mother nature. Expert Opin. Drug Deliv. 7, 403-427. doi: 10.1517/ 17425241003610633

Nguyen, A. T., Prado, M. A., Schmidt, P. J., Sendamarai, A. K., Wilson-Grady, J. T., and Min, M. (2017). UBE2O remodels the proteome during terminal erythroid differentiation. Science 357:eaan0218. doi: 10.1126/science.aan0218

Nguyen, D. B., Ly, T. B., Wesseling, M. C., Hittinger, M., Torge, A., and Devitt, A. (2016). Characterization of microvesicles released from human red blood cells. Cell. Physiol. Biochem. 38, 1085-1099. doi: 10.1159/000443059

Odorizzi, G., Babst, M., and Emr, S. D. (1998). Fablp PtdIns(3)P 5-kinase function essential for protein sorting in the multivesicular body. Cell 95, 847-858. doi: 10.1016/S0092-8674(00)81707-9

Ovchynnikova, E., Aglialoro, F., Bentlage, A. E. H., Vidarsson, G., Salinas, N. D., and von Lindern, M. (2017). DARC extracellular domain remodeling in maturating reticulocytes explains Plasmodium vivax tropism. Blood 130, 14411444. doi: 10.1182/blood-2017-03-774364

Palis, J. (2016). Interaction of the macrophage and primitive erythroid lineages in the Mammalian embryo. Front. Immunol. 7:669. doi: 10.3389/fimmu.2016. 00669

Pan, B. T., Teng, K., Wu, C., Adam, M., and Johnstone, R. M. (1985). Electron microscopic evidence for externalization of the transferrin receptor in vesicular form in sheep reticulocytes. J. Cell Biol. 101, 942-948. doi: 10.1083/jcb.101.3.942

Pridgeon, J. W., Webber, E. A., Sha, D., Li, L., and Chin, L. S. (2009). Proteomic analysis reveals Hrs ubiquitin-interacting motif-mediated ubiquitin signaling in multiple cellular processes. FEBS J. 276, 118-131. doi: 10.1111/j.1742-4658. 2008.06760.x

Quarmyne, M. O., Risinger, M., Linkugel, A., Frazier, A., and Joiner, C. (2011). Volume regulation and $\mathrm{KCl}$ cotransport in reticulocyte populations of sickle and normal red blood cells. Blood Cells Mol. Dis. 47, 95-99. doi: 10.1016/j.bcmd. 2011.04.007

Raiborg, C., and Stenmark, H. (2009). The ESCRT machinery in endosomal sorting of ubiquitylated membrane proteins. Nature 458, 445-452. doi: 10.1038/ nature07961

Rivera, A., Kam, S. Y., Ho, M., Romero, J. R., and Lee, S. (2013). Ablation of the Kell/Xk complex alters erythrocyte divalent cation homeostasis. Blood Cells Mol. Dis. 50, 80-85. doi: 10.1016/j.bcmd.2012.10.002

Sadahira, Y., Yoshino, T., and Monobe, Y. (1995). Very late activation antigen 4vascular cell adhesion molecule 1 interaction is involved in the formation of erythroblastic islands. J. Exp. Med. 181, 411-415. doi: 10.1084/jem.181.1.411

Sahu, R., Kaushik, S., Clement, C. C., Cannizzo, E. S., Scharf, B., and Follenzi, A. (2011). Microautophagy of cytosolic proteins by late endosomes. Dev. Cell 20, 131-139. doi: 10.1016/j.devcel.2010.12.003

Sailaja, Y. R., Baskar, R., Srinivas Rao, C. S., and Saralakumari, D. (2004). Membrane lipids and protein-bound carbohydrates status during the maturation of reticulocytes to erythrocytes in type 2 diabetics. Clin. Chim. Acta 341, 185-192. doi: 10.1016/j.cccn.2003.12.003

Saksena, S., Sun, J., Chu, T., and Emr, S. D. (2007). ESCRTing proteins in the endocytic pathway. Trends Biochem. Sci. 32, 561-573. doi: 10.1016/j.tibs.2007. 09.010
Salomao, M., Chen, K., Villalobos, J., Mohandas, N., An, X., and Chasis, J. A. (2010). Hereditary spherocytosis and hereditary elliptocytosis: aberrant protein sorting during erythroblast enucleation. Blood 116, 267-269. doi: 10.1182/ blood-2010-02-264127

Sandberg, M. B., Nybo, M., Birgens, H., and Frederiksen, H. (2014). Hereditary xerocytosis and familial haemolysis due to mutation in the PIEZO1 gene: a simple diagnostic approach. Int. J. Lab. Hematol. 36, e62-e65. doi: 10.1111/ijlh. 12172

Satchwell, T. J., Bell, A. J., Hawley, B. R., Pellegrin, S., Mordue, K. E., and van Deursen, C. T. (2016). Severe Ankyrin-R deficiency results in impaired surface retention and lysosomal degradation of RhAG in human erythroblasts. Haematologica 101, 1018-1027. doi: 10.3324/haematol.2016.146209

Satchwell, T. J., Bell, A. J., Pellegrin, S., Kupzig, S., Daniels, G., Ridgwell, K., et al. (2011). Critical band 3 multiprotein complex interactions establish early during human erythropoiesis. Blood 118, 182-191. doi: 10.1182/blood-201010-314187

Savina, A., Fader, C. M., Damiani, M. T., and Colombo, M. I. (2005). Rab11 promotes docking and fusion of multivesicular bodies in a calciumdependent manner. Traffic 6, 131-143. doi: 10.1111/j.1600-0854.2004.00 257.x

Savina, A., Furlan, M., Vidal, M., and Colombo, M. I. (2003). Exosome release is regulated by a calcium-dependent mechanism in K562 cells. J. Biol. Chem. 278, 20083-20090. doi: 10.1074/jbc.M301642200

Sawada, K., Krantz, S. B., Dessypris, E. N., Koury, S. T., and Sawyer, S. T. (1989). Human colony-forming units-erythroid do not require accessory cells, but do require direct interaction with insulin-like growth factor I and/or insulin for erythroid development. J. Clin. Invest. 83, 1701-1709. doi: 10.1172/JCI1 14070

Schutte, J., Wang, H., Antoniou, S., Jarratt, A., Wilson, N. K., and Riepsaame, J. (2016). An experimentally validated network of nine haematopoietic transcription factors reveals mechanisms of cell state stability. eLife 5:e11469. doi: 10.7554/eLife.11469

Seu, K. G., Papoin, J., Fessler, R., Hom, J., Huang, G., and Mohandas, N. (2017). Unraveling macrophage heterogeneity in erythroblastic islands. Front. Immunol. 8:1140. doi: 10.3389/fimmu.2017.01140

Shah, S., Huang, X., and Cheng, L. (2014). Concise review: stem cell-based approaches to red blood cell production for transfusion. Stem Cells Transl. Med. 3, 346-355. doi: 10.5966/sctm.2013-0054

Shah, S. N., Gelderman, M. P., Lewis, E. M., Farrel, J., Wood, F., and Strader, M. B. (2016). Evaluation of stem cell-derived red blood cells as a transfusion product using a novel animal model. PLoS One 11:e0166657. doi: 10.1371/journal.pone. 0166657

Simpson, C. F., and Kling, J. M. (1967). The mechanism of denucleation in circulating erythroblasts. J. Cell Biol. 35, 237-245. doi: 10.1083/jcb.35.1.237

Soni, S., Bala, S., Gwynn, B., Sahr, K. E., Peters, L. L., and Hanspal, M. (2006). Absence of erythroblast macrophage protein (Emp) leads to failure of erythroblast nuclear extrusion. J. Biol. Chem. 281, 20181-20189. doi: 10.1074/ jbc.M603226200

Swartz, K. L., Wood, S. N., Murthy, T., Ramirez, O., Qin, G., and Pillai, M. M. (2017). E2F-2 promotes nuclear condensation and enucleation of terminally differentiated erythroblasts. Mol. Cell. Biol. 37:e00274-16. doi: 10.1128/MCB. 00274- 16

Syeda, R., Xu, J., Dubin, A. E., Coste, B., Mathur, J., and Huynh, T. (2015). Chemical activation of the mechanotransduction channel Piezol. eLife 4:e07369. doi: 10.7554/eLife.07369

Tchernia, G., Mohandas, N., and Shohet, S. B. (1981). Deficiency of skeletal membrane protein band 4.1 in homozygous hereditary elliptocytosis. Implications for erythrocyte membrane stability. J. Clin. Invest. 68, 454-460. doi: 10.1172/JCI110275

Toda, S., Segawa, K., and Nagata, S. (2014). MerTK-mediated engulfment of pyrenocytes by central macrophages in erythroblastic islands. Blood 123, 39633971. doi: 10.1182/blood-2014-01-547976

Trakarnsanga, K., Griffiths, R. E., Wilson, M. C., Blair, A., Satchwell, T. J., and Meinders, M. (2017). An immortalized adult human erythroid line facilitates sustainable and scalable generation of functional red cells. Nat. Commun. 8:14750. doi: 10.1038/ncomms 14750

Trakarnsanga, K., Wilson, M. C., Heesom, K. J., Andrienko, T. N., Srisawat, C., and Frayne, J. (2018). Secretory factors from OP9 stromal cells delay differentiation 
and increase the expansion potential of adult erythroid cells in vitro. Sci. Rep. 8:1983. doi: 10.1038/s41598-018-20491-1

Udani, M., Zen, Q., Cottman, M., Leonard, N., Jefferson, S., and Daymont, C. (1998). Basal cell adhesion molecule/lutheran protein. The receptor critical for sickle cell adhesion to laminin. J. Clin. Invest. 101, 2550-2558. doi: 10.1172/ JCI1204

Ullrich, O., Reinsch, S., Urbe, S., Zerial, M., and Parton, R. G. (1996). Rab11 regulates recycling through the pericentriolar recycling endosome. J. Cell Biol. 135, 913-924. doi: 10.1083/jcb.135.4.913

Ulyanova, T., Phelps, S. R., and Papayannopoulou, T. (2016). The macrophage contribution to stress erythropoiesis: when less is enough. Blood 128, 17561765. doi: 10.1182/blood-2016-05-714527

van den Akker, E., Satchwell, T. J., Pellegrin, S., Daniels, G., and Toye, A. M. (2010a). The majority of the in vitro erythroid expansion potential resides in $\mathrm{CD}_{34}{ }^{-}$cells, outweighing the contribution of $\mathrm{CD}_{34}{ }^{+}$cells and significantly increasing the erythroblast yield from peripheral blood samples. Haematologica 95, 1594-1598. doi: 10.3324/haematol.2009.019828

van den Akker, E., Satchwell, T. J., Pellegrin, S., Flatt, J. F., Maigre, M., and Daniels, G. (2010b). Investigating the key membrane protein changes during in vitro erythropoiesis of protein $4.2(-)$ cells (mutations Chartres 1 and 2). Haematologica 95, 1278-1286. doi: 10.3324/haematol.2009.021063

van den Akker, E., Satchwell, T. J., Williamson, R. C., and Toye, A. M. (2010c). Band 3 multiprotein complexes in the red cell membrane; of mice and men. Blood Cells Mol. Dis. 45, 1-8. doi: 10.1016/j.bcmd.2010.02.019

Vidal, M., Sainte-Marie, J., Philippot, J. R., and Bienvenue, A. (1989). Asymmetric distribution of phospholipids in the membrane of vesicles released during in vitro maturation of guinea pig reticulocytes: evidence precluding a role for "aminophospholipid translocase". J. Cell. Physiol. 140, 455-462. doi: 10.1002/ jcp. 1041400308

Wang, J., Ramirez, T., Ji, P., Jayapal, S. R., Lodish, H. F., and Murata-Hori, M. (2012). Mammalian erythroblast enucleation requires PI3K-dependent cell polarization. J. Cell Sci. 125(Pt 2), 340-349. doi: 10.1242/jcs.088286

Wang, J., Wagner-Britz, L., Bogdanova, A., Ruppenthal, S., Wiesen, K., and Kaiser, E. (2013). Morphologically homogeneous red blood cells present a heterogeneous response to hormonal stimulation. PLoS One 8:e67697. doi: 10.1371/journal.pone.0067697

Waugh, R. E., Mantalaris, A., Bauserman, R. G., Hwang, W. C., and Wu, J. H. (2001). Membrane instability in late-stage erythropoiesis. Blood 97, 1869-1875. doi: 10.1182/blood.V97.6.1869

Waugh, R. E., McKenney, J. B., Bauserman, R. G., Brooks, D. M., Valeri, C. R., and Snyder, L. M. (1997). Surface area and volume changes during maturation of reticulocytes in the circulation of the baboon. J. Lab. Clin. Med. 129, 527-535. doi: 10.1016/S0022-2143(97)90007-X

Wickrema, A., Koury, S. T., Dai, C. H., and Krantz, S. B. (1994). Changes in cytoskeletal proteins and their mRNAs during maturation of human erythroid progenitor cells. J. Cell. Physiol. 160, 417-426. doi: 10.1002/jcp.10416 00304

Wiley, J. S., and Shaller, C. C. (1977). Selective loss of calcium permeability on maturation of reticulocytes. J. Clin. Invest. 59, 1113-1119. doi: 10.1172/ JCI108735

Wollmann, M., Gerzson, B. M., Schwert, V., Figuera, R. W., and de Oliveira Ritzel, G. (2014). Not available. Rev. Bras. Hematol. Hemoter. 36, 25-28. doi: 10.5581/1516-8484.20140009

Yamamoto-Tanaka, M., Makino, T., Motoyama, A., Miyai, M., Tsuboi, R., and Hibino, T. (2014). Multiple pathways are involved in DNA degradation during keratinocyte terminal differentiation. Cell Death Dis. 5:e1181. doi: 10.1038/ cddis.2014.145

Yang, L., Andrews, D. A., and Low, P. S. (2000). Lysophosphatidic acid opens a $\mathrm{Ca}^{++}$channel in human erythrocytes. Blood 95, 2420-2425.

Yokoyama, T., Etoh, T., Kitagawa, H., Tsukahara, S., and Kannan, Y. (2003). Migration of erythroblastic islands toward the sinusoid as erythroid maturation proceeds in rat bone marrow. J. Vet. Med. Sci. 65, 449-452. doi: 10.1292/jvms. 65.449

Yoshida, H., Kawane, K., Koike, M., Mori, Y., Uchiyama, Y., and Nagata, S. (2005). Phosphatidylserine-dependent engulfment by macrophages of nuclei from erythroid precursor cells. Nature 437, 754-758. doi: 10.1038/nature03964

Yuditskaya, S., Suffredini, A. F., and Kato, G. J. (2010). The proteome of sickle cell disease: insights from exploratory proteomic profiling. Expert Rev. Proteomics 7, 833-848. doi: 10.1586/epr.10.88

Zarychanski, R., Schulz, V. P., Houston, B. L., Maksimova, Y., Houston, D. S., and Smith, B. (2012). Mutations in the mechanotransduction protein PIEZO1 are associated with hereditary xerocytosis. Blood 120, 1908-1915. doi: 10.1182/ blood-2012-04-422253

Zermati, Y., Fichelson, S., Valensi, F., Freyssinier, J. M., Rouyer-Fessard, P., and Cramer, E. (2000). Transforming growth factor inhibits erythropoiesis by blocking proliferation and accelerating differentiation of erythroid progenitors. Exp. Hematol. 28, 885-894. doi: 10.1016/S0301-472X(00)00 $488-4$

Conflict of Interest Statement: The authors declare that the research was conducted in the absence of any commercial or financial relationships that could be construed as a potential conflict of interest.

Copyright (c) 2018 Ovchynnikova, Aglialoro, von Lindern and van den Akker. This is an open-access article distributed under the terms of the Creative Commons Attribution License (CC BY). The use, distribution or reproduction in other forums is permitted, provided the original author(s) and the copyright owner(s) are credited and that the original publication in this journal is cited, in accordance with accepted academic practice. No use, distribution or reproduction is permitted which does not comply with these terms. 